\title{
THE ISSUE OF SHADING PHOTOVOLTAIC INSTALLATION CAUSED BY DUST ACCUMULATION ON THE GLASS SURFACE
}

\begin{abstract}
The issue of accumulation of dust and other pollutants on the surface of photovoltaic modules was thoroughly analysed over the years. One of the first surveys in this field of knowledge linked pollutant accumulation on the module surface with transmittance loss of its glass covering, which leads to lessened amount of solar radiation reaching solar cells. First stage of this accumulation process is linear transparency loss, and second stage - molecule agglomeration and settlement some grains on the already existing layer of dust. Additionally, the pace of working parameters reduction for photovoltaic installation is influenced by the type of dust itself. Molecules with smaller grains cover the surface much more densely, therefore limiting the amount of light passing though the top glass layer far more than molecules with bigger grains. The aim of the carried out study was to find the relationship between dust surface density and change in electrical parameters. Such approach makes it possible to compare electrical and physical parameters of different photovoltaic modules. Additionally, glass coverage itself was noted to have a significant impact on the overall decrease in working parameters of PV modules.
\end{abstract}

Keywords: photovoltaic modules, surface soiling, power decrease, efficiency decrease

\section{Introduction}

The ongoing trend of reducing fossil fuel usage favours rapid development of green energy, so it becomes easily accessible for personal utilisation. Since photovoltaics belongs to the group of alternative energy sources, companies and private investors wish to maximise potential working conditions and thus - generated energy. One factor that is inseparably connected to the outdoor placement of such installation is ongoing dust accumulation on its top glass surface. Shading is an issue that greatly influences the decrease in energy yield that can be obtained from PV installation $[1,2]$. It reduces the amount of light reaching solar cells [3], therefore causing current value to drop [4, 5], and resulting in lessened maximum power [6,7] as well as efficiency [8].

The process of pollutant build-up is characterised by two phases [9, 10]. Firstly, there is a linear reduction of transparency for glass layer, as molecules cover the surface uniformly. Then, the start to settle on top of already existing coverage and also on the yet uncovered glass. The rate of transmittance reduction is linked to tilt angle of the module itself. The steeper the tilt angle is, the slower pollution agglomerates on the surface as its adhesion is poor, as is presented in Figure 1a [11].

\footnotetext{
${ }^{1}$ Department of Energy Conversion and Storage, Faculty of Chemistry, Gdańsk University of Technology, ul. G. Narutowicza 11/12, 80-233 Gdańsk, Poland, phone +48 583471874

*Corresponding author: ewa.klugmann-radziemska@pg.edu.pl
} 
a)

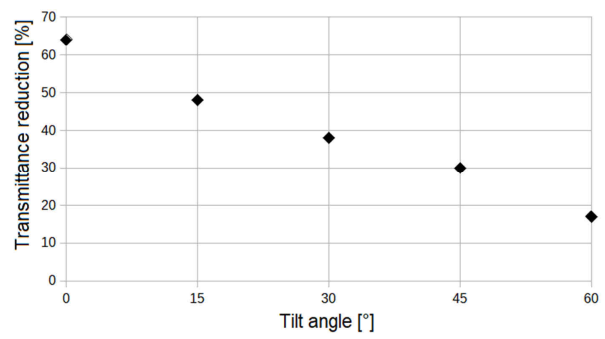

b)

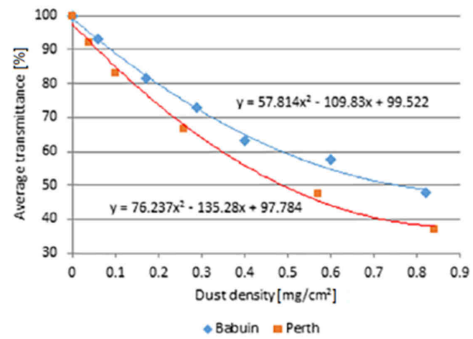

Fig. 1. a) Transmittance reduction for different tilt angles of glass surface to the ground (on the basis of [11]), b) transmittance for dust accumulated on the glass surface in two different locations [12]

Another important factor linked to dust agglomeration is indirect thermal effect described and analysed by Jaszczur et al. [13]. Such effect occurs after dust build-up, which causes module operating temperature to increase. Thus, pollution accumulation not only limits the amount of solar irradiation reaching solar cells, but also leads to the rise of surface temperature in PV device, ensuring quicker loss of efficiency.

The localisation of photovoltaic installation near regions with increased industrial activity, heavy traffic, agricultural crops or deserts, has a major impact on dust composition. A throughout study conducted by El-Shobokshy and Hussein concluded that finer dust particles cause grater reduction of generated power, since they are stacked densely near one another and block light more efficiently [14]. Recent investigation performed by Tanesab confirms this finding, by analysing soil from two much different locations - Perth in Australia, and Babuin in Indonesia [12]. Dust gathered from Babuin, had more porous structure and was proven to cause less reduction in maximum power (Fig. 1b).

Additionally, frequent rainfalls also affect the process of pollutant agglomeration. It could reduce thickness of soil layer, provided that precipitation is at high intensity [15]. Drizzle, light rain or just high humidity causes greater soiling effect, because it elevates adhesion [16, 17].

The presented study focuses simultaneously on two types of research - one in the external conditions, with dust deposited naturally on the surface of three different photovoltaic modules, and the other carried out completely inside laboratory hall with three types of pollutants artificially deposited on top of the surface of two solar devices. It was conducted in Gdansk, at University of Technology, which is in northern Poland. The purpose of natural dust analysis was to specify the rate of natural dust agglomeration as well as defining influence from external factor - precipitation. Additionally, the artificial dust part of research was supposed to draw comparison between efficiency reduction in the function of surface density of soil unit.

\section{Methodology and experimental setup}

The test stand was built with the intention of placing it on the rooftop together with photovoltaic modules mounted on its frame. This warranted a small scale imitation of dust adhesion occurring naturally in external conditions on photovoltaic installations. The chosen building is located on Gdansk University of Technology (GUT) campus, which is in a seaside town in northern Poland with coordinates $54^{\circ} 37^{\prime} \mathrm{N}, 18^{\circ} 62^{\prime}$ E. Placement of 
each solar device is captured in photograph in Figure 2. They are facing directly south and are attached to a metal rack at $34^{\circ}$ tilt angle with respect horizontal surface. However, before taking them outside, each module surface was scraped off of any previously gathered dust and rinsed with isopropyl alcohol. The same mounting position was kept through January 2019 to November 2019. At the end of the year dust accumulated on the surface of the reference solar device, CLC010-12P, was collected. It will be discussed in this paper as dust 1 .

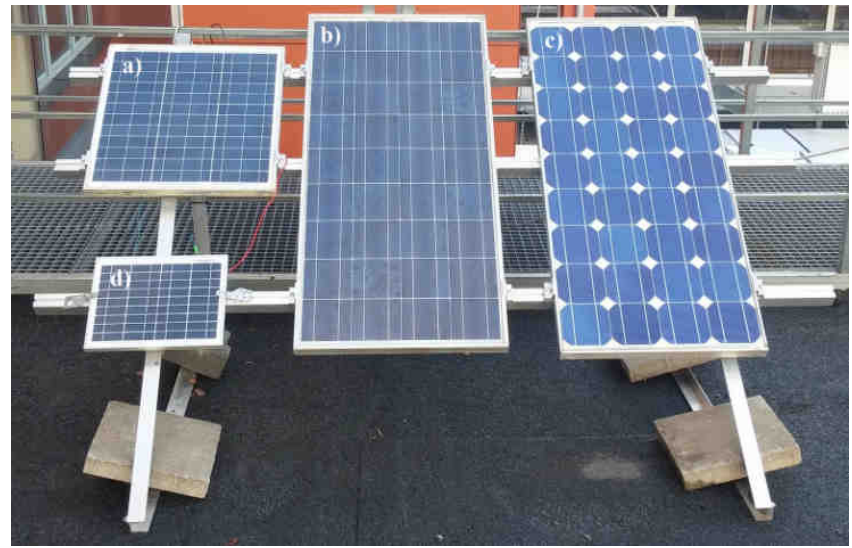

Fig. 2. Photovoltaic modules in natural dust study: a - MWG-30, b - AP-7105, c - STP-085, d - CLC010-12P

To check the changes in working conditions of three modules (MWG-30, AP-7105, STP-085) were dismantled once a month and taken inside laboratory hall. There, they were tested at Standard Test Conditions on the measuring unit, according to the scheme presented in Figure 3. Module CLC010-12P was constantly kept outside, since it was intended to only gather dust without any interference.
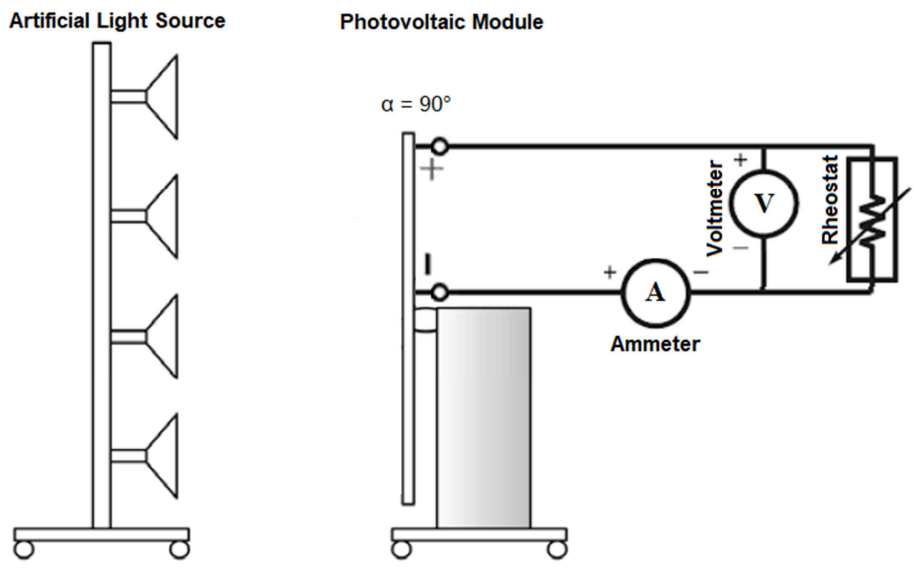

Fig. 3. Scheme of the measuring unit in the laboratory 
Constant irradiance value $1000 \mathrm{~W} / \mathrm{m}^{2}$ and uniform light distribution was achieved by adjusting separately each halogen lamp out of the total number of eight. It was checked beforehand for three modules, as a pyranometer readout was taken and recalculated as an average from evenly distributed points on the glass surface - twelve for AP-7105 and STP-085, nine for MWG-30. Moreover, measurement was paused each time the module surface exceeded $27{ }^{\circ} \mathrm{C}$ to let it cool down. Specification of all measuring units is listed in Table 1.

Table 1

Technical data of station with halogen laps and all gauging devices

\begin{tabular}{|c|c|c|c|}
\hline Instrument & Producer & Serial number & Description \\
\hline Light source & G.U.N.T. Hamburg & HL-313.01 & $\begin{array}{c}8 \text { halogen lamps } \\
\text { power of } 1 \text { lamp: } 1000 \mathrm{~W}\end{array}$ \\
\hline $\begin{array}{l}\text { Current-voltage } \\
\text { measuring unit }\end{array}$ & G.U.N.T. Hamburg & ET-250 & $\begin{array}{l}\text { Voltage measuring range: } 0-200 \mathrm{~V} \\
\text { Current measuring range: } 0-20 \mathrm{~A} \\
\text { Irradiance measuring range: } 0-3000 \mathrm{~W} / \mathrm{m}^{2} \\
\text { Tilt angle measuring range: } 0-90^{\circ} \\
\text { Temperature range: } 0-+100{ }^{\circ} \mathrm{C}\end{array}$ \\
\hline Pyranometer & Kipp \& Zonen & METEON 07080865 & $\begin{array}{c}\text { Measuring accuracy: } 0.1 \% \\
\text { Operating temperature: }-10-+40{ }^{\circ} \mathrm{C}\end{array}$ \\
\hline Pyrometer & Fluke & $\begin{array}{l}62 \text { mini IR } \\
\text { Thermometer }\end{array}$ & $\begin{array}{c}\text { Measuring accuracy: } \pm 1.5^{\circ} \mathrm{C} \\
\text { Operating temperature: }-30-+500{ }^{\circ} \mathrm{C} \\
\text { Sensor: laser } \\
\text { Standard measurement distance: } 2 \mathrm{~m}\end{array}$ \\
\hline
\end{tabular}

Current and voltage data were gathered after connecting solar device to ammeter, voltmeter and external load. Afterwards, all three modules were once again set on the metal frame outside. Seasonal efficiency was calculated as the average vale from the sum of monthly efficiencies for each meteorological time of the year, according to equation (1). Seasonal efficiency decline was obtained on the basis of formula (2) with regard to seasonal efficiency in winter.

$$
\begin{gathered}
\eta_{S}=\frac{\sum_{i}^{k} \eta_{i}}{k} \\
\eta_{D}=\frac{\eta_{S}^{W}-\eta_{S}}{\eta_{S}^{W}} \cdot 100 \%
\end{gathered}
$$

where: $\eta_{S}$ - seasonal efficiency in chosen meteorological season [\%], $\eta_{i}$ - efficiencies in meteorological season [\%], $k$ - number of months with gathered data in meteorological season $[-], \eta_{D}$ - normalised seasonal efficiency decline [\%], $\eta_{S}{ }^{W}$ - seasonal efficiency in winter [\%].

In parallel to the external pollution study, research was conducted with artificially deposited dust. Basic reference unit for comparing working parameters of photovoltaic modules was chosen as surface mass density. Artificial pollutants were gathered from three different locations - roads at Gdansk University of Technology (dust 2), sand beach area near the walking pier in Gdansk, Brzezno district (dust 3) and sand beach area near the tram loop in Gdansk, Brzezno district (dust 4). After gathering around $500 \mathrm{~g}$ of each soil, they were sieved 20 times by $1 \mathrm{~mm}$ netted strainer to ensure only loose matter remained. To apply it evenly on photovoltaic module surface, the pollutant was once more sieved, this time over the whole surface, and then sprayed with isopropyl alcohol, so that it would stick 
heavily. Surface density was calculated at the end of each current-voltage measurement, when dust was scraped off of module surface and weighed. Then, the mass was divided by surface area and thus exact value was obtained in $\mathrm{g} / \mathrm{m}^{2}$ unit. A few trials for dust adhesion were performed beforehand to establish how much soil should be sieved over the module to acquire surface density in the range of $0-13 \mathrm{~g} / \mathrm{m}^{2}$. Measurement of current and voltage values was carried out as was previously explained for Figure 2. Two photovoltaic modules were polluted with three artificial soil to plot relation between normalised decrease of efficiency as a function of dust surface density. It was calculated accordingly to equation (3)

$$
\eta_{N}=\frac{\eta_{P}}{\eta_{C}}
$$

where: $\eta_{N}$ - normalised efficiency decline [-], $\eta_{P}$ - efficiency of a photovoltaic module with a polluted glass surface [\%], $\eta_{C}$ - efficiency of a photovoltaic module with a clean glass surface [\%].

Data sheet of all photovoltaic modules tested inside the laboratory hall

\begin{tabular}{|c|c|c|c|c|c|}
\hline & CLC010-12P & MWG-20 & MWG-30 & AP-7105 & STP-085 \\
\hline$\eta[\%]$ & 10.5 & 11.2 & 12.5 & 11.8 & 13.1 \\
\hline$P_{\text {MAX }}\left[\mathrm{W}_{\text {peak }}\right]$ & 10.0 & 20.0 & 30 & 75.0 & 85.0 \\
\hline$V_{\text {MAX }}[\mathrm{V}]$ & 17.5 & 17.2 & 17.5 & 17.0 & 17.1 \\
\hline$I_{\text {MAX }}[\mathrm{A}]$ & 0.57 & 1.17 & 4.4 & 4.4 & 4.97 \\
\hline$V_{\mathrm{OC}}[\mathrm{V}]$ & 22.0 & 21.8 & 21.0 & 21.0 & 21.4 \\
\hline$I_{\mathrm{SC}}[\mathrm{A}]$ & 0.63 & 1.23 & 4.8 & 4.8 & 5.32 \\
\hline Length $[\mathrm{mm}]$ & 340 & 505 & 680 & 1210 & 1195 \\
\hline Width $[\mathrm{mm}]$ & 280 & 353 & 353 & 526 & 541 \\
\hline Thickness $[\mathrm{mm}]$ & 1.7 & 28 & 25 & 35 & 30 \\
\hline Weight $[\mathrm{kg}]$ & 1.1 & 2.3 & 3.9 & 8.2 & 8.0 \\
\hline Cell type & Polycrystalline & Polycrystalline & Polycrystalline & Monocrystalline & Polycrystalline \\
\hline
\end{tabular}

The list of all sampling points for natural as well as artificial dust research is included in Table 3.

Sampling points for all four types of dusts

\begin{tabular}{|c|c|c|}
\hline Dust number & Sampling point description & Coordinates \\
\hline 1 & $\begin{array}{c}\text { Gathered from the surface of CLC010-12P module in } \\
\text { external conditions after one year deposition }\end{array}$ & $54^{\circ} 37^{\prime} \mathrm{N}, 18^{\circ} 62^{\prime} \mathrm{E}$ \\
\hline 2 & Gathered from the roads on GUT campus, nearby \\
Chemistry Faculty & $54^{\circ} 37^{\prime} \mathrm{N}, 18^{\circ} 62^{\prime} \mathrm{E}$ \\
\hline 3 & $\begin{array}{c}\text { Gathered from sand beach area in close proximity to the } \\
\text { walking pier in Brzezno district }\end{array}$ & $54^{\circ} 41^{\prime} \mathrm{N}, 18^{\circ} 64^{\prime} \mathrm{E}$ \\
\hline 4 & $\begin{array}{c}\text { Gathered from sand beach area in close proximity to the } \\
\text { tram loop in Brzezno district }\end{array}$ & $54^{\circ} 41^{\prime} \mathrm{N}, 18^{\circ} 62^{\prime} \mathrm{E}$ \\
\hline
\end{tabular}

\section{SEM analysis}

Scanning electron microscopy (SEM) was applied to visualise the structure of all four types of dusts (Fig. 4). It was performed by SEM microscope FEI Quanta FEG 250. The measurement was performed at following parameters: acceleration voltage at $20 \mathrm{kV}$, 
amplifier time constant at $1.6 \mu \mathrm{s}$, resolution at $131.2 \mathrm{eV}$ and take-off angle $43.2^{\circ}$ (dust 1 ), $43^{\circ}$ (dust 2), $43.6^{\circ}$ (dust 3, dust 4). Magnitude was kept at 42 for dust 1, 34 for dust 2, 49 for dust 3 and 53 for dust 4 . Natural pollutant noticeably differs from the artificially collected soils, as some of its grains exhibit sharply defined edges, while others are build with more resemblance to sponge. In a few places they seem to merge into each other, in other places there is a stacking pattern. It indicates that an agglomeration process has already happened over the time span of one year. Such effect was observed by other research groups, pointing to two distinct phases of dust accumulation. First, there is uniform distribution of pollutant over the whole surface, and afterwards agglomeration - as molecules also gather on top of previous layer of soil. Dust 2 is made of grains with two varying sizes - the smaller ones have an average diameter equal to $0.2 \mathrm{~mm}$, and diameter for bigger ones is around $0.45 \mathrm{~mm}$. Moreover, cracks appear in some places. The last two, dust 3 and 4, were gathered from similar location, near the beach. This could be the reason why their grains are smaller in diameter, less fractured and with smooth, almost polished look for the surface and edges. Dust 3 has the average grain diameter of $0.23-0.36 \mathrm{~mm}$, while for dust 4 it is $0.22-0.33 \mathrm{~mm}$.
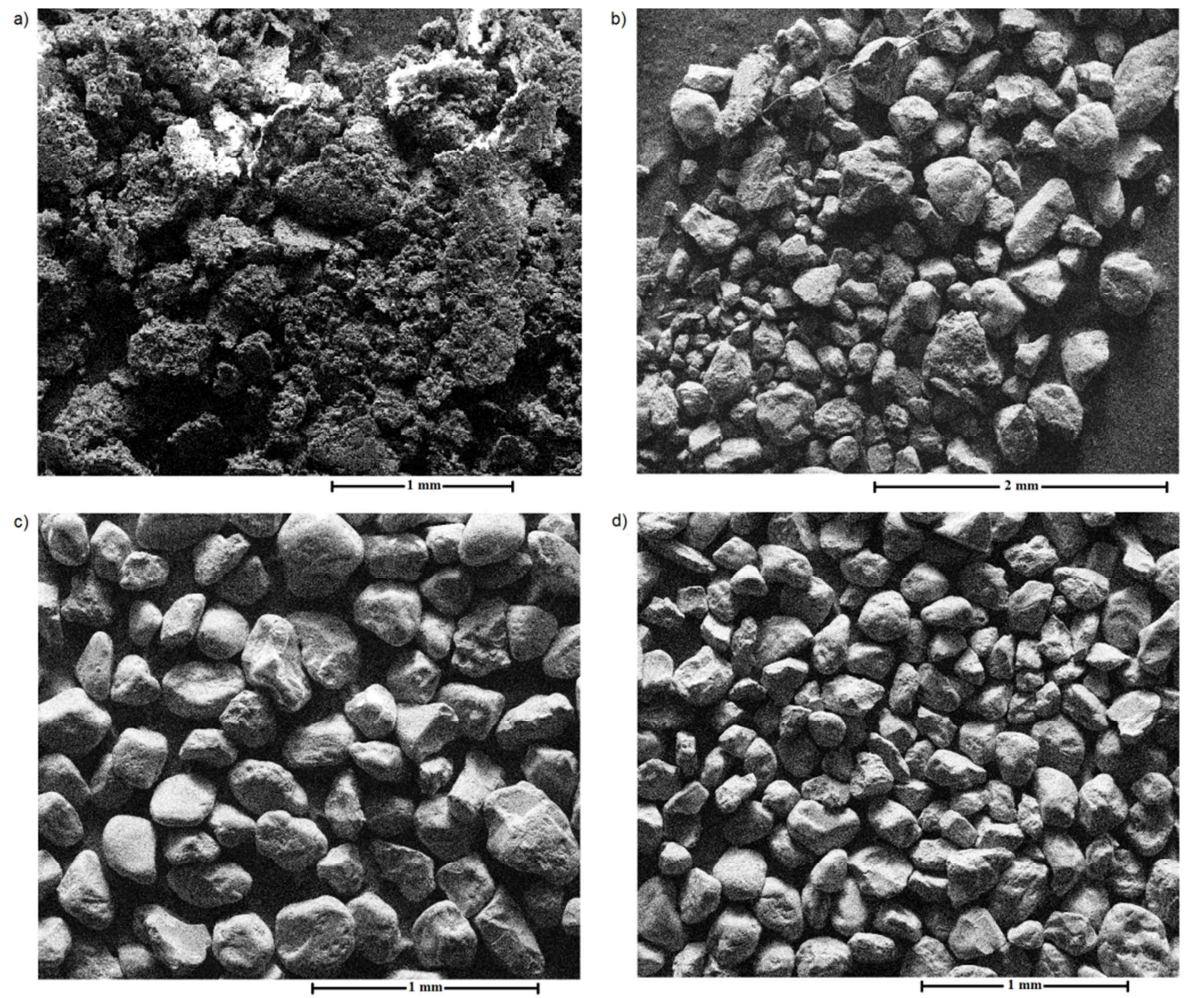

Fig. 4. SEM photograph of: a) dust 1, b) dust 2, c) dust 3, d) dust 4 


\section{EDS analysis}

Energy dispersive spectroscopy (EDS) measurement was performed via FEI Quanta FEG 250 with added EDS analyser for the elemental compositions analysis. Measurement parameters were the same as specified for SEM analysis. Spectrum presented in Figure 5, indicates that dust 1 consists of considerable portion of silicon, oxygen, potassium and aluminium. Trace elements of iron, calcium, magnesium, sulphur and titanium also appear. Such diversified composition is a result of sampling point located in a close vicinity to a frequently used roads surrounding Gdansk University of Technology campus. Additionally during the accumulation period in 2019 construction work took place directly under Chemistry building rooftop. Dust 2 confirms this prediction, as it comprises mainly calcium, silicon, oxygen and aluminium, with trace elements of magnesium and iron. Dusts 5 and 6 are less differentiated element-wise due to their sampling point location near the beach. Their spectra exhibit two noticeably strong peaks from silicon and oxygen, and two weak signals from aluminium, iron and calcium. Appearing carbon peak could be originating from carbon tape used during the measurement, however it may also be a trace element in the dust composition.
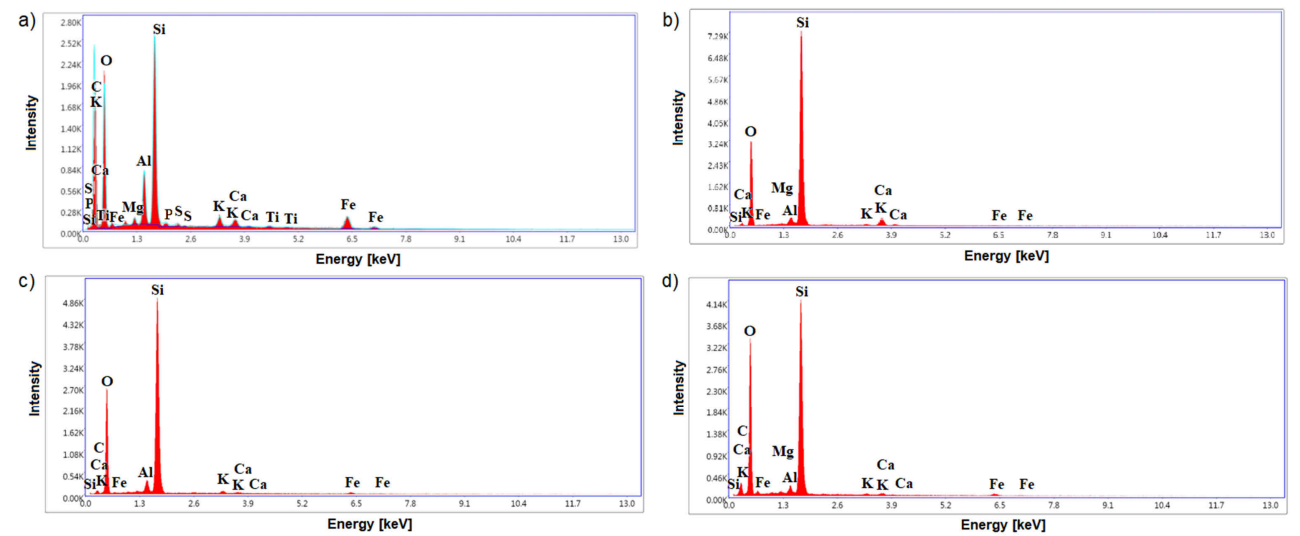

Fig. 5. EDS graph of: a) dust 1, b) dust 2, c) dust 3, d) dust 4

Element concentration measured for every type of dust in the experiment

Table 4

\begin{tabular}{|c|c|c|c|c|}
\cline { 2 - 5 } \multicolumn{1}{c|}{} & \multicolumn{3}{c|}{ Concentration of element [\%] } & Dust 4 \\
\hline Element & Dust 1 & Dust 2 & 2.30 & 0.84 \\
\hline $\mathrm{Al}$ & 2.46 & 1.67 & 0.35 & 0.41 \\
\hline $\mathrm{Ca}$ & 0.80 & 3.73 & 1.10 & 0.98 \\
\hline $\mathrm{Fe}$ & 2.78 & 0.47 & - & 0.22 \\
\hline $\mathrm{Mg}$ & 0.38 & 0.17 & 32.97 & 22.06 \\
\hline $\mathrm{Si}$ & 8.33 & 41.23 & - & - \\
\hline $\mathrm{Ti}$ & 0.16 & - & 10.63 & 0.22 \\
\hline $\mathrm{C}$ & 49.18 & - & 0.55 & 55.99 \\
\hline $\mathrm{K}$ & 0.78 & 0.37 & 52.11 & - \\
\hline $\mathrm{O}$ & 35.05 & 52.37 & - & - \\
\hline $\mathrm{P}$ & 0.00 & - & - & \\
\hline $\mathrm{S}$ & 0.08 & - & & \\
\hline
\end{tabular}


The list of concentration percentage for all of the elements and each dust type $(1,2,3$ and 4) is presented in Table 4.

\section{Seasonal efficiency results}

Time frame for this part of study started in January 2019 and ended in November 2019. Apart from one day a month, when the measurement was performed at Standard Test Conditions, all three photovoltaic modules were kept outside and as such - prone to experiencing atmospheric dust build-up. Using gathered current-voltage data, efficiency values for MGW-30, AP-7105 and STP-085 were calculated according to formula (1), and the exact data are included in Table 5.

Efficiency values for MWG-30, AP-7105 and STP-085

Table 5

\begin{tabular}{|c|c|c|c|c|}
\cline { 2 - 5 } \multicolumn{1}{c|}{} & \multicolumn{3}{c|}{ Seasonal efficiency [\%] } \\
\hline Photovoltaic module & Winter & Spring & Summer & Autumn \\
\hline MWG-30 & 12.0 & 10.3 & 10.0 & 10.8 \\
\hline AP-7105 & 8.5 & 8.1 & 7.1 & 7.7 \\
\hline STP-085 & 10.4 & 9.7 & 9.0 & 9.5 \\
\hline
\end{tabular}

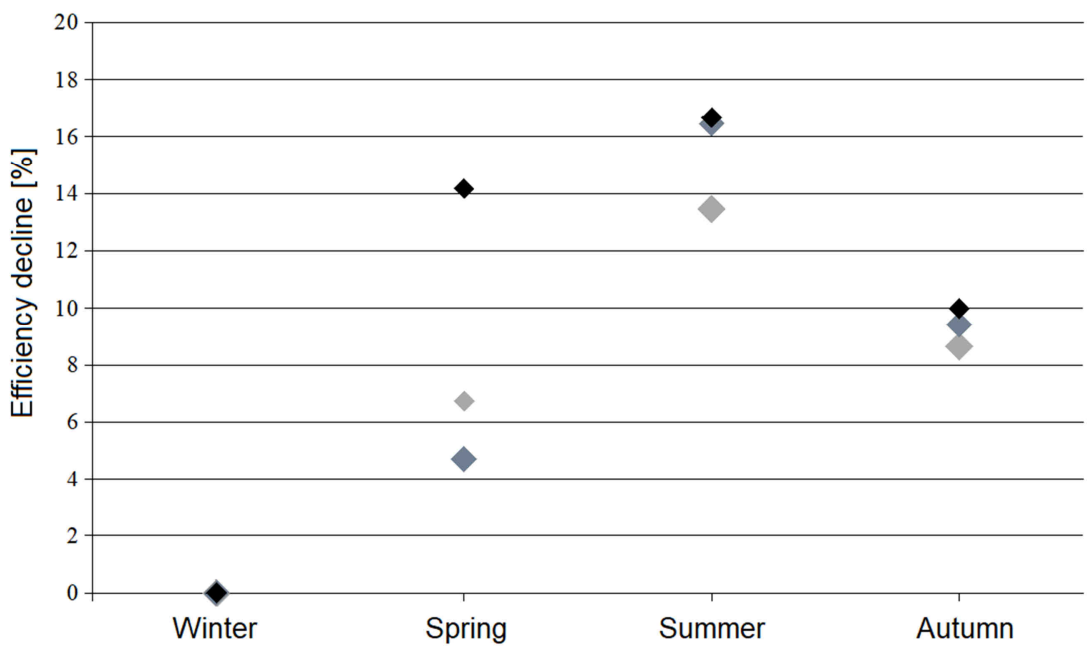

Fig. 6. Normalized seasonal efficiency decline in year 2019 after natural dust deposition on the surface of photovoltaic module modules: $(\diamond)$ MWG-30, (») AP-7105, (») STP-085

Additionally, a graph is presented in Figure 6 to show a relation obtained from equation (2) - between efficiency decline and each meteorological season. MWG-30 experienced the biggest drop of efficiency when first subjected to external factors, as it reached almost $15 \%$, however in the next season its working conditions deteriorate at a much slower rate. The opposite outcome was observed for AP-7105 and STP-085. In the initial stage their efficiency reduction did not exceed $7 \%$, but in summer it is already way over $12 \%$ for both modules. What is also notice worthy, is the partial efficiency recovery for autumn months. At that time the overall efficiency decline was in the range of 8-10\% 
for all three modules. It may indicate to external factors affecting the dust layer, as heavy rainfalls occur in this season with high intensity for north of Poland. The possible outcome is rinsing off a part of already accumulated pollution.

\section{Normalised efficiency for artificial dusts}

The results of artificial dust analysis, obtained from calculation (3), are presented in graphs in Figure 7. This study was intended to imitate natural dust accumulation in external conditions. To achieve such result, dust 2, 3 and 4 were sieved over two polycrystalline photovoltaic modules, namely MWG-20 and CLC010-12P, which respectively have $8.8 \%$ and $10.6 \%$ efficiency, assessed at Standard Test Conditions before each current-voltage measurement in laboratory hall. All three contaminants caused a linear decline in normalised efficiency and as such it may be linked to the first phase of dust settlement reported by other research groups [9-11]. Despite both modules being manufactured in the same technology with regard to solar cells, they have various response to contamination. Such phenomena could be explained by the type of glass layer, because it is most likely not of the same structure, as modules were produced by different companies. This was proven in another studies, supervised by Cabanillas and Munguia [6] and Gandhi et al. [8], where they do not detect correlation between the type of a solar cell and response in efficiency after dust accumulation.

Based on the relation for all types of artificial dusts MWG-20 is less phased with glass surface pollution, since normalised efficiency value never falls below $94 \%$, even for higher order of surface dust density. On the other hand, already a small amount of dust is able to limit working parameters of CLC010-12P and $94 \%$ value for normalised efficiency is reached for $3 \mathrm{~g} / \mathrm{m}^{2}$. When the contamination reaches $10 \mathrm{~g} / \mathrm{m}^{2}$ and above normalised efficiency is reduced by $10 \%$. The average efficiency reduction caused by $1 \mathrm{~g} / \mathrm{m}^{2}$ of dust equals to $0.38 \%$ for MWG-20 and $0.77 \%$ for CLC010-12P.
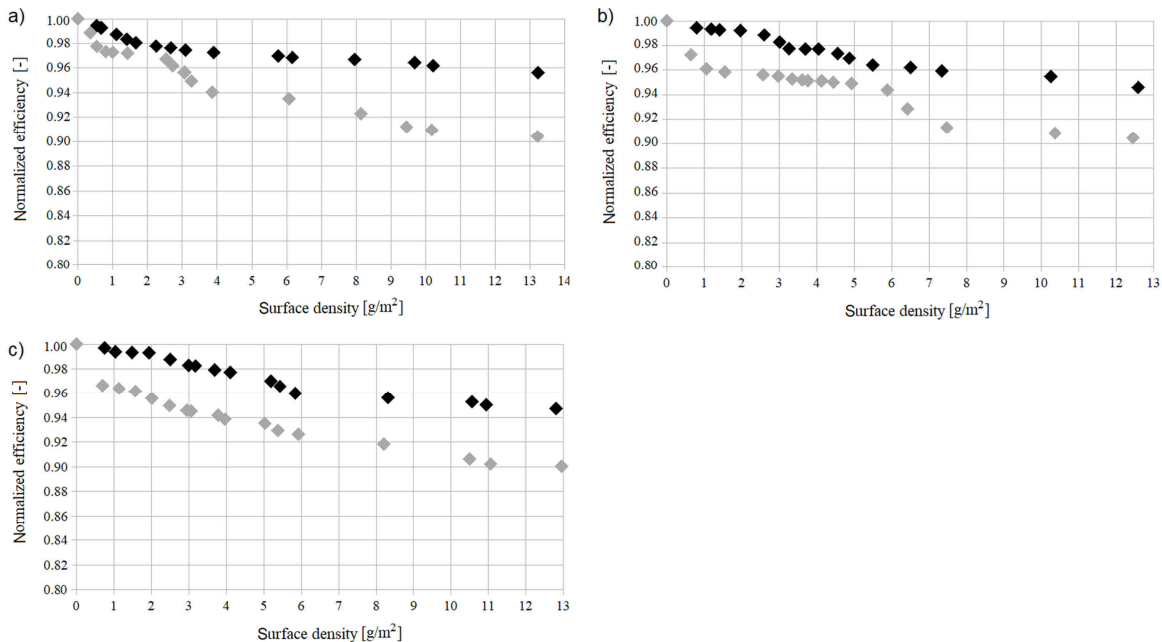

Fig. 7. Normalised efficiency decline as a function of dust surface density for: a) dust 2, b) dust 3 , c) dust 4, covering surface of two PV modules: $(\diamond)$ MWG-20 and ( $\diamond$ CLC010-12P 


\section{Conclusion}

Dust settlement on the photovoltaic module surface is an issue irreversibly linked to the location and orientation of the whole installation. Those factors influence the rate of contaminant deposition, the type of soil and any possible partial cleansing after precipitation. It is noteworthy to mention that the exposure time does not impact dust build-up in a linear way.

To provide insight into soiling effect in temperate coastal climate, both natural and artificial dust study was conducted at Gdansk University of Technology in year 2019. For a natural dust analysis it was stated that a steady decline of efficiency is present, however once the autumn season starts it enables a slight recovery of working parameters. This is due to heavy rainfalls appearing frequently at this time of year. Simultaneously, artificial pollutant survey helped to draw a linear relationship between efficiency drop and varying surface density, which was expected based on the literature review. As long as artificial dust is applied in a uniform manner over the whole glass surface, all three types of contaminants may be utilised for the purpose of laboratory analysis of the soiling effect. Different rate of efficiency decrease was observed for two polycrystalline modules, which was explained by the top layer of glass causing varying response in dust adhesion to the surface.

\section{Acknowledgements}

The authors gratefully acknowledge the contribution of M. Winiarski from the Department of Solid-State Physics, Faculty of Applied Physics and Mathematics, at Gdansk University of Technology for performing SEM and EDS measurements.

\section{References}

[1] Rodziewicz T, Rajfur M, Wacławek M. Ecol Chem Eng S. 2020;27(1);9-39. DOI: 10.2478/eces-2020-0001.

[2] Klugmann-Radziemska E, Rudnicka M. Ecol Chem Eng S. 2020;27(3);335-46. DOI: 10.2478/eces-2020-0021.

[3] Vivar M, Herrero R, Anton I, Martinez-Moreno F, Sala G, Blakers AW, et al. Sol Energy. 2010;84:1327-35. DOI: 10.1016/j.solener.2010.03.031.

[4] Al-Hasan A, Ghoneim AA. Int J Sustain Energy. 2005;24:187-97. DOI: 10.1080/14786450500291834.

[5] Abderrezek M, Fathi M. Elektron Elektrotech. 2018;24:41-5. DOI: 10.5755/j01.eie.24.1.20158.

[6] Cabanillas R, Munguia H. J Renew Sustain Energy. 2011;3. DOI: 10.1063/1.3622609.

[7] Rao A, Pillai R, Mani M, Ramamurthy P. Energy Procedia. 2013;54:690-700. DOI: 10.1016/j.egypro.2014.07.310.

[8] Gandhi AT, Gupta A, Vijay BS. Int J Renew Energy Res. 2014;4:628-34. Available from: https://www.ijrer.org/ijrer/index.php/ijrer/article/view/1390/pdf.

[9] Al-Hasan A. Sol Energy. 1998;63:323-33. DOI: 10.1016/S0038-092X(98)00060-7.

[10] Beattie NS, Moir RS, Buffoni G. Renew Energy. 2012;48:448-52. DOI: 10.1016/S0038-092X(98)00060-7.

[11] Wang J, Gong H, Zou Z. JOCET. 2017;5:217-21. DOI: 10.18178/jocet.2017.5.3.372.

[12] Tanesab J, Parlevliet D, Whale J, Urmee T. Sustain Energy Technol Assess. 2019;31:347-54. DOI: 10.1016/j.seta.2018.12.024.

[13] Jaszczur M, Hassan Q, Teneta J, Styszko K, Nawrot W, Hanus R. MATEC Web Conf. 2018;240:04005. DOI: $10.1051 /$ matecconf/201824004005.

[14] El-Shobokshy MS, Hussein FM. Renew Energy. 1993;3:585-90. DOI: 10.1016/0960-1481(93)90064-N.

[15] Styszko K, Jaszczur M, Teneta J, Hassan Q, Burzynska P, Marcinek E, et al. Environ Sci Pollut Res. 2019;26:8393-401. DOI: 10.1007/s11356-018-1847-z.

[16] Paudyal BR, Shakya SR. Sol Energy. 2016;135:103-10. DOI: 10.1016/j.solener.2016.05.046.

[17] Yadav SK, Bajpai U. IJETER. 2017;5:67-72. DOI: 10.1016/0960-1481(93)90064-N. 